\title{
Treatment of ITER plasma facing components: Current status and remaining open issues before ITER implementation
}

\author{
C. Grisolia ${ }^{\mathrm{a}, *}$, G. Counsell ${ }^{\mathrm{b}}$, G. Dinescu ${ }^{\mathrm{c}}$, A. Semerok ${ }^{\mathrm{d}}$, N. Bekris ${ }^{\mathrm{e}}$, P. Coad ${ }^{\mathrm{b}}$, \\ C. Hopf ${ }^{\mathrm{f}}$, J. Roth ${ }^{\mathrm{f}}$, M. Rubel ${ }^{\mathrm{g}}$, A. Widdowson ${ }^{\mathrm{b}}$, E. Tsitrone ${ }^{\mathrm{a}}$, JET EFDA Contributors \\ ${ }^{a}$ Association Euratom/CEA, CEA Cadarache, DSM/DRFC/SIPP, 13108 Saint Paul Lez Durance, France \\ b Association Euratom/UKAEA, Culham Science Centre, Abingdon OX14 3DB, UK \\ ${ }^{\mathrm{c}}$ Association Euratom/MdEC, NILPRP, P.O. Box MG-36, 077125 Magurele-Bucharest, Romania \\ ${ }^{d}$ CEA Saclay, DEN/DPC/SCP/LILM, Bat. 467,91191Gif sur Yvette, France \\ e Forschungszentrum Karlsruhe, Postfach 3640, 76021 Karlsruhe, Germany \\ ${ }^{\mathrm{f}}$ Max-Planck-Institut fur Plasmaphysik, Euratom Association, D-85748 Garching, Germany \\ $\mathrm{g}$ Alfven Laboratory, Royal Institute of Technology, Association EURATOM-VR, 10044 Stockholm, Sweden
}

\begin{abstract}
The in-vessel tritium inventory control is one of the most ITER challenging issues which has to be resolved to fulfil safety requirements. This is due mainly to the presence of carbon as a constituent of plasma facing components (PFCs) which leads to a high fuel permanent retention. For several years now, physics studies and technological developments have been undertaken worldwide in order to develop reliable techniques which could be used in ITER severe environment (magnetic field, vacuum, high temperature) for in situ tritium recovery. The scope of this contribution is to review the present status of these achievements and define the remaining work to be done in order to propose a dedicated work program.

Different treatment techniques (chemical treatments, photonic cleaning) will be reviewed. In the frame of ITER, they will be compared in terms of fuel removal rate as well as surface accessibility, type of production (gas or particulates), ability to clean mixed material.

And lastly, consequences of bulk trapping observed in tokamak on the techniques currently under development will be addressed.
\end{abstract}

Published with Fusion Engineering and Design: Fus. Eng. Des. 82 (2007) 2390-2398

\section{INTRODUCTION}

Treatment of plasma facing components (PFCs) is a major issue for ITER operation. Wall conditioning after shutdown as well as during plasma operation is mandatory to allow reproducible plasma start up, safe current ramp up and recycling control [1]. Treatments are also needed to control tritium inventory and fulfil safety requirements. Several treatments have been proposed in the past decade in order to remove the carbon co-deposited layers observed in current tokamaks using graphite or carbon fibre composites (CFC) as part of their PFCs and in which a high concentration of tritium is often observed [2].

Like in current machines, ITER will use carbon in the divertor and will therefore experience high material erosion. Skinner and Federici [3] have estimated that the expected ITER deposition rate of tritium will be of the order of $5 \mathrm{~g}$ of tritium per pulse. This implies the necessity of an overnight removal rate of more than $100 \mathrm{~g}$ of tritium. This quantity corresponds to $1000 \mathrm{~g}$ of material removal capability with an atomic ratio of tritium over carbon of 0.5 (and an equal atomic ratio of deuterium).

Several current results reviewed by Krieger [4] have shown the importance of fuel trapping in gaps (and voids) on the total fuel inventory. Retention in gaps can be as much as twice the retention observed on PFC directly wetted by the plasma. Techniques must be able to control the fuel trapping in these

*E-mail: christian.grisolia@cea.fr "difficult to access" regions.

Several well-known treatments based on radio frequency (rf) heating systems such as ICRH conditioning [5] have been considered as possible solutions. These techniques can be used in the presence of permanent magnetic fields, and are efficient and reliable, but only surfaces facing the rf plasma are treated. These treatments will be not presented hereafter due to lack of space but results of interest are reviewed in [5].

This paper will be focused mainly on several techniques which are currently under development or which have been recently tested in tokamaks. Main results will be presented as well as the ability of the methods to treat gaps, and the remaining open issues which need to be addressed in order to implement these treatments in the ITER environment.

Chemical processes such as oxidation which is very promising will be addressed [6-8] since oxygen can be injected in between operation and gas can reach hidden surfaces. Other chemical techniques based on a nitrogen plasma torch will be also presented as well as the estimated treatment removal rate.

Interaction of light with material is another process that is used to recover the trapped tritium via ablation or heating of carbon co-deposited layers. The flash lamp technique [9] which has proven its capability to operate in a tokamak environment, and laser interaction with matter offer very interesting alternatives $[10,11]$. Both techniques can be used by remote handling and laser can probably treat areas which are difficult to access like voids or castellation thanks to the small size of the laser spot light. In the following we will show that if, as in the JET tokamak [12], an accumulation of carbon layers is observed in limited areas then ablation techniques are 


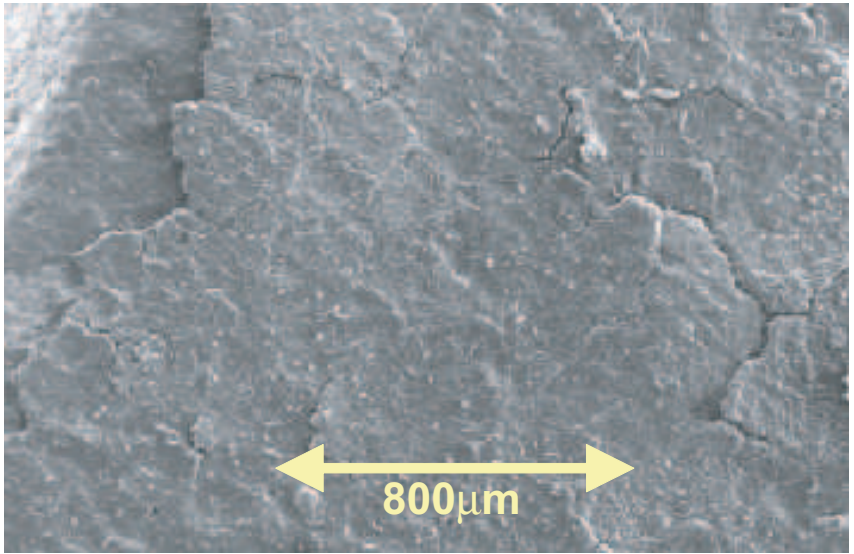

FIG. 1: Evidence of flaking of deposited material after oxygen treatment at high surface temperature.

sufficiently efficient to accomplish the ITER needs when coupled with dedicated dust removal system.

In Tore Supra, the only worldwide actively cooled device able to realise plasma of more than $400 \mathrm{~s}$, almost $50 \%$ of the injected fuel seems to be lost in the wall during plasma operation [13]. This bulk trapping process seems to be confirmed by laboratory studies. This observation, if extrapolated to ITER, has major consequences on fuel control and this will be discussed at the end of the paper.

\section{CHEMICAL TREATMENT: OXIDATION}

Oxygen has the capability to reach all the surfaces of the in vessel components especially hidden and voids structures. Oxidation seems to be a very powerful technique to remove all the codeposited layer by chemical reaction and then recover the tritium trapped in the form of tritiated water or hydrocarbons [31].

Several trials have been done in the past few years in tokamak or laboratory environments.

Oxidation of an rf protection antenna has been undertaken at TEXTOR [14], the antenna being out of the vessel. It has been shown that this treatment is effective at surface temperature exceeding $300{ }^{\circ} \mathrm{C}$ which are well above the ITER operating temperature. The removal rate slows down rapidly in presence of metal inclusions and flaking of deposited material is often observed after treatment (see Fig. 1).

Glow discharge has been also used with a mixture of $\mathrm{He}$ and oxygen $(2 \%)$ in the AUG tokamak [15]. The removal rate of such technique expressed in term of carbon removal rate is low $\left(\sim 1 \times 10^{-4} \mathrm{gC} / \mathrm{s}\right)$ but could be increased by a factor 10 using more in vessel anodes and better power supply. The surfaces treated are facing the glow plasma leaving the hidden surfaces untreated. As for the pure oxidation process, the glow production vanishes in presence of metal inclusions.

Due to its poor results in presence of mixed materials oxidation does not seem suitable for co-deposited layer removal in the ITER environment.

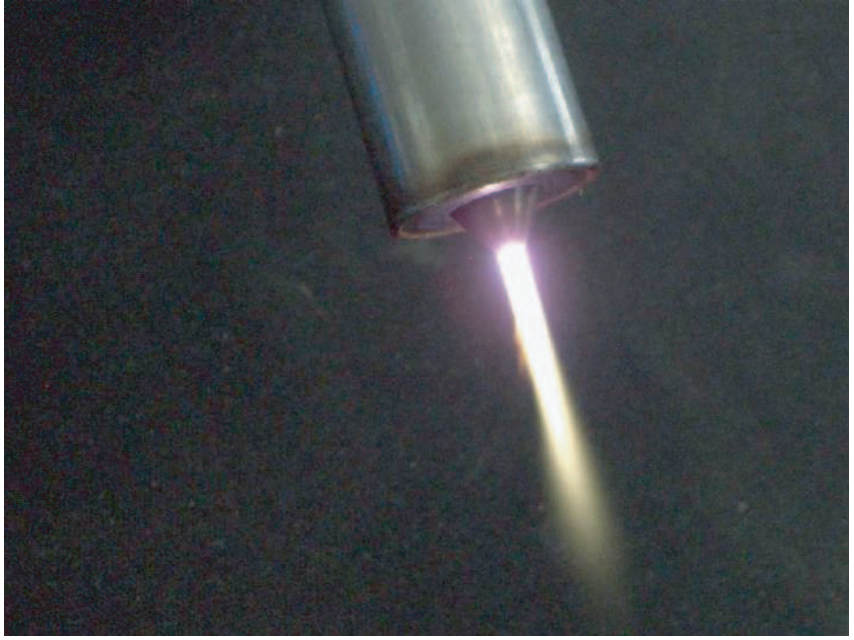

FIG. 2: Picture of a nitrogen plasma torch in operation. The plasma plume is $4 \mathrm{~cm}$ long and the diameter of the torch itself is $2 \mathrm{~cm}$.

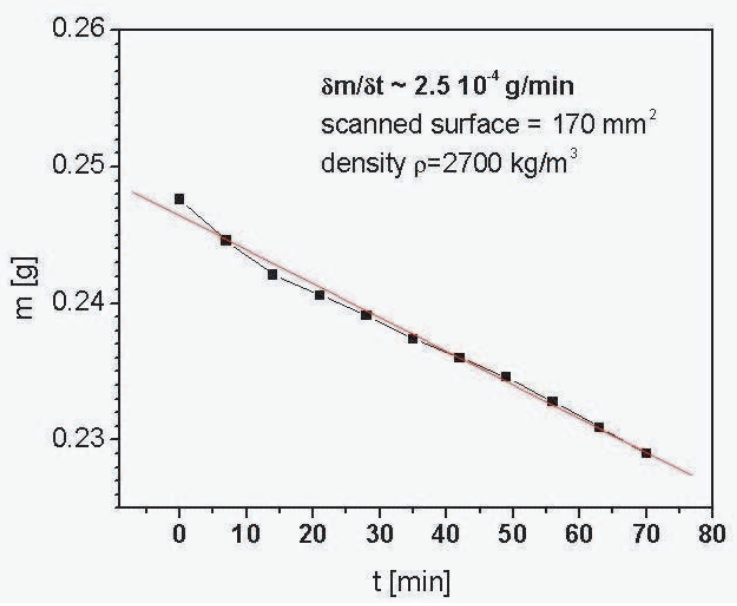

FIG. 3: Removal rate of the $\mathrm{N}_{2}$ plasma torch measured by gravimetry (rf power $\sim 300 \mathrm{~W}$, distance to the surface $\sim 8 \mathrm{~mm}$, gas flow $\sim 2300 \mathrm{sccm}$ ).

\section{CHEMICAL TREATMENTS: NITROGEN PLASMA TORCH}

\section{A. Laboratory assessment}

Low-pressure expanding plasma jets are used routinely in surface treatment devices. A new rf plasma torch operating at atmospheric pressure was realized and tested at NILPRP in Romania [16]. In order to use this technique remotely, a new smaller plasma torch has been developed. This source has a diameter of $2 \mathrm{~cm}$ (see Fig. 2).

When used with nitrogen gas, chosen to chemically react with carbon, the gas flow varies from 2000 to $9000 \mathrm{sccm}$ (standard cubic centimetre per minute, $1 \mathrm{sccm}=1.66 \times$ $10^{-3} \mathrm{Pam}^{3} / \mathrm{s}$ ) with respectively $250-600 \mathrm{~W}$ of $\mathrm{rf}$ power. When the torch is placed at $15 \mathrm{~mm}$ to the material, the surface 
temperature can reach $800^{\circ} \mathrm{C}$. This operating mode is stable without any arcs. First laboratory tests have been done with CFC samples from Tore Supra coated with co-deposited layers of several $\mu \mathrm{m}$ of depth. A special scanning system was developed in order to treat the surface of the tile in an automatic way. For these preliminary assessments, the $\mathrm{N}_{2}$ plasma torch was placed at $8 \mathrm{~mm}$ from the surface, the rf power was $300 \mathrm{~W}$ and the gas flow $2300 \mathrm{sccm}$.

The removal rate of the treatment is measured by gravimetry (see Fig. 3) and is $10^{-5} \mathrm{gC} / \mathrm{s}$ the interacting surface being $170 \mathrm{~mm}^{2}$.

\section{B. Open issues}

The removal rate observed is very low compared to more efficient techniques (see hereafter laser or flash lamp). However, this $\mathrm{N}_{2}$ plasma torch enhances chemical processes and only gases are produced. Moreover, this small device can operate with different active gases which are injected directly onto the zone to be treated. This area is brought to high temperature surface $\left(\sim 800^{\circ} \mathrm{C}\right)$ which activates chemical processes. Tests are scheduled in order to improve the material removal rate by adjusting the operating regime and to check the consequences of treatment on surface properties.

Preliminary observations indicate that the plasma penetrates in voids and gaps giving the capability to treat hidden surfaces. Plasma torch technique could be complementary to laser or flash lamp to treat voids.

When the torch is operating in a low-pressure environment, the plasma plume dimension is increased. This could be the solution to get a reliable remote handling $(\mathrm{RH})$ technique provided that the surface temperature stays over $300-400^{\circ} \mathrm{C}$. Trials are ongoing in order to evaluate the best compromise between surface temperature and distance between torch and material surfaces.

Since this $\mathrm{T}$ recovery technique is based on chemical enhanced reactions using active gases, the removal rate observed with carbon could deteriorate if mixed materials are present (as for oxidation treatment with metal inclusion). In 2007, the plasma torch technique will be assessed in the JET beryllium handling facility (BeHF) using tritiated tiles in order to evaluate the effectiveness with real tokamak material.

And lastly, this technique need to operate in magnetic fields, and tests must be undertaken to confirm that the torch could operate in such severe environment.

\section{PHOTONIC CLEANING: FLASH LAMP ABLATION}

\section{A. JET assesment}

This industrial technique was applied in JET in 2004 showing the tokamak feasibility of the method [17]. The flash lamp tests were achieved using the JET Remote Handling device to move the water-cooled flash lamp in front of the inner divertor tiles (see Fig. 4).

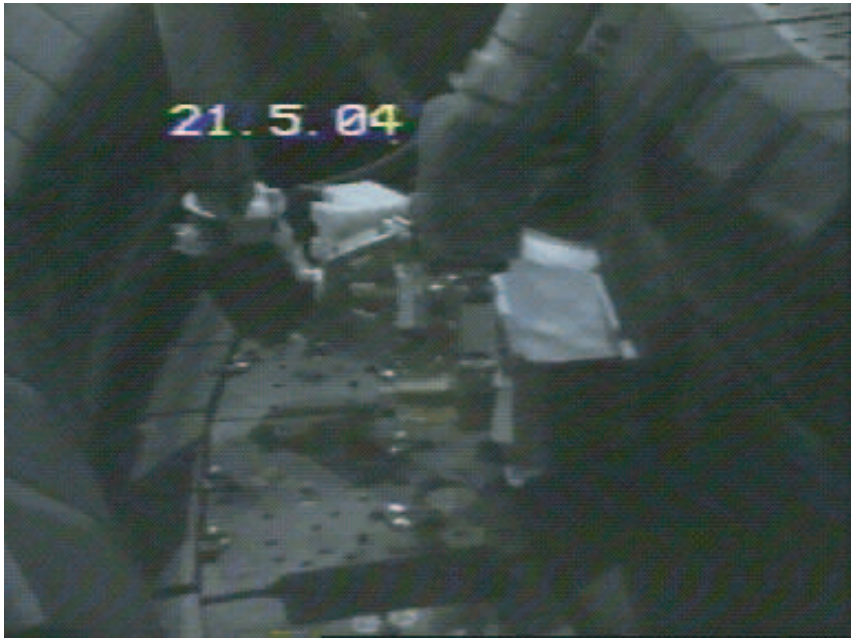

FIG. 4: Picture of the flash lamp installed on the JET RH boom during in situ trials in 2004.

Several complementary trials have been done in 2005 in the JET BeHF using a special tools developed to treat a horizontal target from the JET MKII-GB/SRP divertor [18]. This tile was covered by a thick codeposit of $150-250 \mu \mathrm{m}$ that is rich in tritium and deuterium. The flash lamp used produces a $500 \mathrm{~J}$ energy pulse released in $140 \mu$ s with a spectral bandwidth from $200 \mathrm{~nm}$ to $1 \mu \mathrm{m}$. The lamp is focussed on a surface of $30 \mathrm{~cm}^{2}$ leading to an energy density up to $6 \mathrm{~J} / \mathrm{cm}^{2}$. The distance between the front reflector cavity and the surface is $20-40 \mathrm{~mm}$. Several positions of the tile were treated with up to 2600 pulses at flash lamp pulse repetition rate of $5 \mathrm{~Hz}$.

The tile was then analysed by several techniques (SIMS, ion beam analysis, scanning electron microscopy) allowing comparison between treated and un-treated areas. The main results are as follows:

- Up to $90 \mu \mathrm{m}$ of co-deposit was removed from the tile surface corresponding to a rate of $10^{-3} \mathrm{gC} / \mathrm{s}$ (see Fig. 5).

- The total amount of tritium released corresponds to $40 \%$ of the $\mathrm{T}$ inventory of the treated area ( $3 \mathrm{GBq})$. All tritium is released in gaseous form. This is due to the fact that the surface does not reach the temperature needed for ablation. Moreover, codeposited layers removal could also be driven by the strong UV output from the lamp leading to a break of the chemical bonds giving birth to gaseous products more than micro-particles.

- H-isotopes are desorbed to a depth of $\sim 7 \mu \mathrm{m}$ beyond the removal zone. This corresponds to the heat penetration into the co-deposit during the $140 \mu$ s flash leading of a heating of the material up to $700 \mathrm{~K}$.

- A build up of Ni (and other metallic impurities) is observed at the surface. This accumulation seems to slow down the $\mathrm{T}$ production in the course of the trails. 


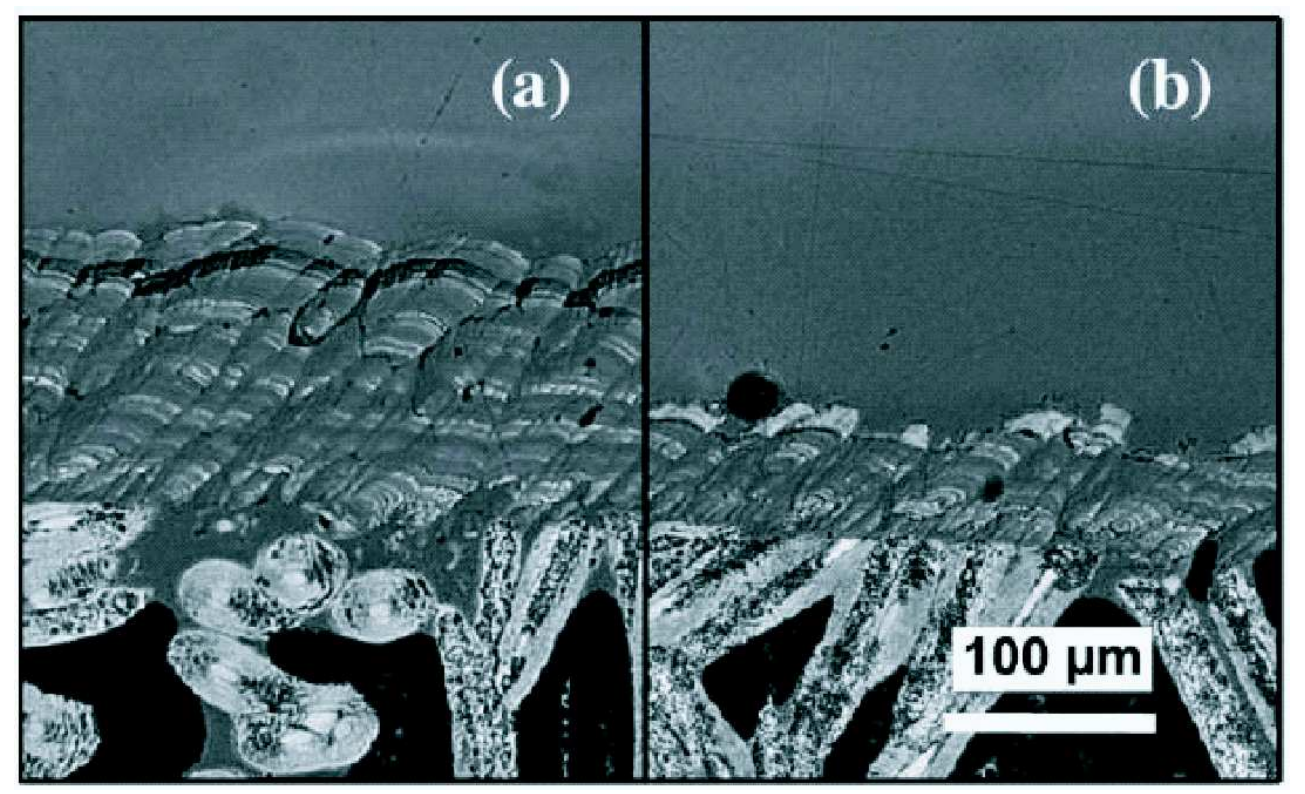

FIG. 5: Optical microscopy of cross-section for untreated (a) and treated (b) tiles.

\section{B. Open issues}

The flash lamp method is very robust and reliable. The removal rate is close to the ITER needs and can be easily improved by using an array of flash lamps in order to cover a wide range of surfaces to be treated.

The current limitations of this method which have to be studied are the following:

- Due to its size, this method is not suitable for constrained zones such as divertor corners or backs of limiters. However, adapted optics could be developed in order to direct the light onto these "difficult to access" surfaces.

- Gaps will be difficult to treat and assessment of gap cleaning removal rate must be undertaken.

- This method is well adapted to light absorbing material as has been proven in JET. Operating with nonabsorbing pieces like metal will lead to a substantial increase of power to get the same rise in temperature. In parallel, a high flux will be reflected. This can induce a perturbation on the system itself but also on the environment. These consequences have to be addressed.

- Access and remote handling are needed to use flash lamp in situ. However, nowadays, no robot has been developed which can operate in the presence of magnetic field. In that condition, and even if this technique is one of the most efficient, it can be only considered for monthly ITER treatments when the permanent magnetic field will be set to zero.

\section{PHOTONIC CLEANING: LASER ABLATION}

\section{A. Laboratory and BeHF assessments}

Laser ablation is used on an industrial scale to vaporize material and obtain controlled layer deposition or chemical analysis of the surface component. It is also used to clean surfaces or to decontaminate hot cells by removing painting and then insuring efficient decontamination [19].

This technique has been also successfully applied on carbon and carbon layers coming from tokamaks. Layer ablation is obtained by carbon sublimation, e.g., raising rapidly the sample surface temperature to $4000 \mathrm{~K}$ [20]. Pulse heating is set at a very short time duration (e.g. $100 \mathrm{~ns}$ ) in order to get ablation without any heat diffusion from the surface to the bulk material.

First assessments have been done in laboratory using TEXTOR tiles covered with a thick deposited carbon layer of $50 \mu \mathrm{m}$ depth at the maximum. Due to differences in the thermal properties, the bulk and the codeposited materials experience different ablation threshold fluences $\left(F_{\text {th }}\right)$. For the bulk graphite material, $F_{\text {th }}$ is five times greater than for the deposited layer (see Fig. 6).

This process is independent of the material environment since the threshold energy for the layer ablation is the same in air and in inactive gases like argon.

Thanks to the observed different ablation threshold fluences, the ablation process is an auto-limiting one. Indeed, if the laser fluence is set to a value which is above the layer $F_{\text {th }}$ but lower than the bulk material $F_{\text {th }}$, the ablation process will take place only if the layer is still present and will stop when the bulk surface is reached. During this selective experiment in which only layers are removed, no bulk modification and/or destruction have been experienced. 


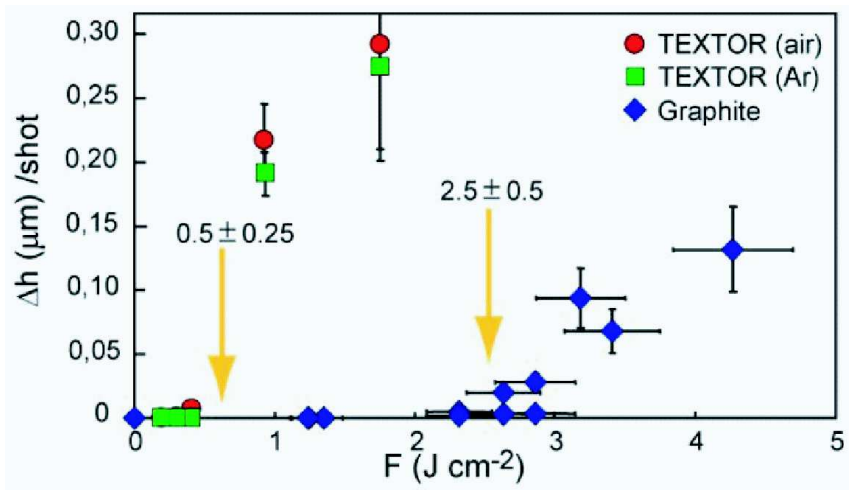

FIG. 6: Evidence of different fluence threshold for deposited material ( $\mathbf{\square}$ in argon and $\bullet$ in air) and for bulk graphite $(\bullet)$.

In order to develop a dedicated laser system which can be mounted on a tokamak robot, several constraints have to be fulfilled.

The first one is the use of an optical fibre in order to transmit the laser light. However, the in situ robot adjustment relative to the PFC surfaces is a complicated issue. The distance between the robot and the wall has not to be too short and the accuracy of the positioning must of the order of centimetres.

An ytterbium fibre laser has been chosen. This laser is operating on a fundamental wavelength of $1060 \mathrm{~nm}$ at $20 \mathrm{kHz}$ pulse repetition rate. Pulse duration is $120 \mathrm{~ns}$. The beam divergence at the exit of the fibre is limited allowing a focalisation length of $40 \pm 2 \mathrm{~cm}$ which permits an easy robot positioning. The laser fluence on the ablated surface is $2 \mathrm{~J} / \mathrm{cm}^{2}$ with a beam diameter of $250 \mu \mathrm{m}$. During the ablation experiment, a galvanometric scan is used to move the laser spot, by steps of $25 \mu \mathrm{m}$, on the treated sample.

Result of this automatic ablation treatment on a TEXTOR tile gives a removal rate of $10^{-2} \mathrm{gC} / \mathrm{s}$. If the ITER deposited layers are localised in area as they are in JET (e.g., several localised square meters), a laser ablation system mounted on one (or more) robot could accomplish this task overnight.

This ablation device has to be tested in a real tokamak environment and a dedicated apparatus has been designed in order to be tested in the JET vessel, attached to the remote handling boom. Due to lack of shutdown opportunity, in-vessel assessments would not be possible before 2009. However, tests have been undertaken in June 2006 in the JET BeHF using the device shownin Fig. 7. Several tiles from the JET divertor were treated successfully.

Preliminary observations have shown that the laser ablation technique is a very powerful tool leading to an apparent complete coating removal in a single scan.

Detritiated zones will be characterised using ion beam analysis [21], calorimetry [22] and combustion of cored samples [23].

Due to its flexibility, laser ablation is easily mounted on a robot. Developments are currently undertaken in order to use the EFDA Articulated In-vessel Arm (AIA) [24] project to transport an ablation device. In-vessel tests are considered for 2008 in theTore Supra tokamak.

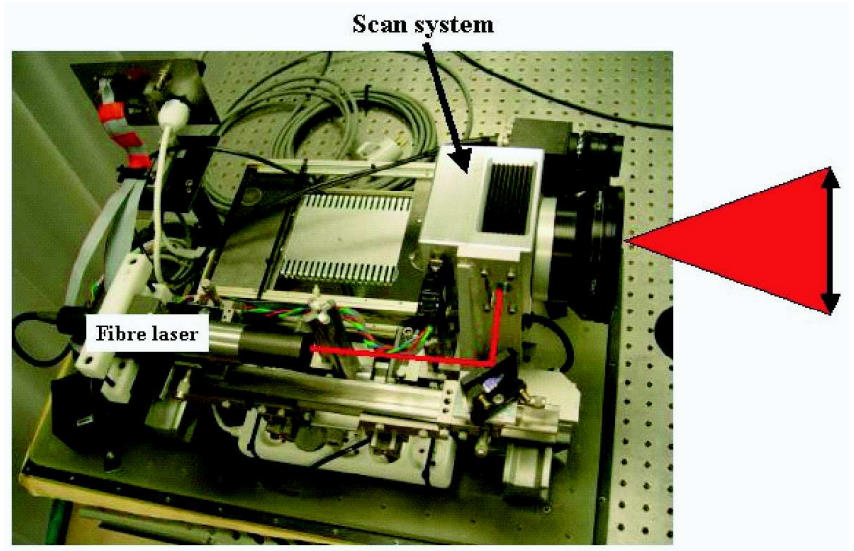

FIG. 7: Experimental arrangement used during the trials in the JET BeHF in June 2006. Black triangle illustrates the angular range of laser beam (not at geometrical scale).

\section{B. Open issues}

As it has been shown above, the removal rate of the laser ablation technique is ITER compatible. The galvanometric scan has to be actively cooled in order to operate in the ITER environment and this is achievable. However, there are still some pending issues. The scanning system used is not compatible with operation in a permanent magnetic field. R\&D is ongoing to develop a scanning tool which could operate in presence of a permanent magnetic field. Most of the ablation products are dusts. A special tool must also be incorporated in order to recover the dust created during the ablation process. This could be done with an aspirating system which will have also to work under magnetic environment. If this aspiration system is removed from the vessel in order to avoid field effects, studies must be undertaken in order to check the dust recovery capability of this remote suction hardware.

Due to the small size of the laser spot, laser ablation is one of the techniques which can be considered to treat the tiles gaps. Trials are needed to prove the removal rate of the technique to access these almost hidden surfaces which are the side of the tiles. In that case, dust treatment will also need to be improved in order to recover the particulates emitted during the treatment and which will probably tend to be retained in the tile gaps.

\section{CONSEQUENCES OF BULK MATERIAL TRITIUM TRAPPING}

As it has been observed in Tore Supra, almost $50 \%$ of the injected fuel is lost in the wall during plasma operation [25]. In this actively cooled machine, dedicated to long pulse operation, the process of trapping seems to be unclear. It is supposed that the deposited layers trap the majority of the fuel. However, it is also possible that deuterium/tritium could be trapped inside the CFC itself. This hypothesis seems to be corroborated by results from some laboratories [13] but also 
by Bekris [22] who has observed deep diffusion of tritium in JET CFC tiles. Tritium was detected at a substantial level even at the centre of a tile with a thickness of some centimetres. Fuel bulk trapping is one order of magnitude higher in CFC than in pyrolytic graphite probably due to surface diffusion within the voids of the highly porous CFC material. If it turns out that tritium diffusion is the source of the fuel lost, techniques which are proven to be efficient with codeposited matters such as laser or flash lamp ablation will be insufficient to control the ITER fuel cycle. No treatments that are proposed at present could remove this deep-trapped tritium.

Several techniques used during or in between plasma shots could help to lower codeposited layer formation. As an example, injection of $\mathrm{N}_{2}$ into the plasma induces a reduction by a factor 5 of the co-deposit formation [26, 27]. Radiative plasma termination is also a powerful tool to recover $\mathrm{T}$ from co-deposited layers that are heated to temperatures higher than $1000 \mathrm{~K}$ by the quasi-uniform pulse radiation obtained after a massive gas injection [28]. However, all these techniques are inducing codeposited layer treatment and in some case removal. But it is not confirmed at all that they will control $\mathrm{T}$ diffusion in the bulk material especially during long plasma shot operation.

Another solution in order to block deep tritium trapping process could be to implement a diffusion transport barrier on top of the graphite and CFC bulk [29]. Trials have been done in PISCES-B where carborane was injected in a low energy plasma $(40 \mathrm{eV})$ and a boron carbide protecting film was deposited to protect the PFC surfaces and implement this diffusion barrier [29]. Nevertheless, this technique needs to be validated in real tokamak configuration and energy fluxes.

If no reliable technique is found in the near future, before the tritium phase of the ITER operation, graphite and especially CFC will have to be removed from the fusion machine as proposed by JET [30] and definitively replaced by metal walls which experience lower tritium trapping.

\section{CONCLUSIONS}

Several treatments have already the capability to achieve the ITER requirements in term of co-deposited layer removal if these layers are located in restricted surface areas.

Flash lamp and laser ablation are the most powerful tools already available. These techniques are derived from indus- trial systems and have proven to be very reliable.

They can be used remotely. From that point of view, the laser which uses a fiber to transport the laser light is the most suitable system. Flash lamp has been successfully tested in presence of magnetic field. An adapted laser scanning must be developed. Nevertheless, it has to be pointed out that, in order to use these techniques in the presence of a permanent magnetic field, a robot is needed. No current development plans exist to build a $\mathrm{RH}$ device compatible with this magnetic constraint.

Laser and flash lamps are valid to treat mixed material even if, in the latter case, a build up of high $\mathrm{Z}$ material at the surface is observed.

Different types of products come from the treatment of layers in a tokamak. Gases are produced by all the chemical processes and by the flash lamp, and will have to be treated by the ITER active gas handling system which needs to be sized up to treat these products especially if active gases need to be injected. In the case of laser ablation, the majority of the production is dust and a special tool must be developed in order to recover these byproducts. However, this is a general subject since plasma operation will also produce lot of dust that has to be managed as well.

Fifty percent of the tritium trapped could be found in the gaps and castellations of ITER tiles. This is a major problem to deal with. Trials have to be undertaken as soon as possible to check the removal rate of the available techniques in case of gaps (and hidden surfaces) treatment.

It is obvious that current developments are aimed at tritium trapped in layers which are not spread on all the in-vessel surfaces. If, as a consequence of the ITER operation, codeposited layers will be homogeneously distributed, the techniques based on laser or flash lamp will continue to be available but the time of treatment will be much longer. Several carrier robots would need to be used to treat efficiently higher surface areas.

There is currently no treatment which can achieve bulk tritium recovery. If the current tokamak and laboratory observation are confirmed, fuel control will be achieved by playing with operating tools such as better fuel injection (with higher fuelling efficiency) or plasma terminated disruption to try to control this bulk tritium trapping. However, the final solution could be to remove all the carbon and CFC porous material from the in-vessel PFC and to replace them by metal components.
[1] C. Grisolia, J. Bucalossi, T. Loarer, Vacuum 60 (2001) 147152.

[2] T. Tanabe, N. Bekris, P. Coad, J. Nucl. Mater. 313-316 (2003) 478-490;

C.H. Skinner, J.P. Coad, G. Federici, Phys. Scripta T111 (2004) 92-97;

N. Bekris, C. Caldwell-Nichols, L. Doerr, J. Nucl. Mater. 307311 (2002) 1649-1654.

[3] C.H. Skinner, G. Federici, Phys. Scripta T124 (2006) 18-22.

[4] K. Krieger, W. Jacob, D.L. Rudakov, J. Nucl. Mater. 363-365
(2007) 870-876.

[5] E. de la Cal, E. Gauthier, Plasma Phys. Contr. Fusion 47 (2005) 197-218.

[6] V. Philipps, G. Sergienko, A. Lyssoivan, J. Nucl. Mater. $363-$ 365 (2007) 929-932.

[7] S. Alberici, J.P. Coad, H.K. Hinssen, J. Nucl. Mater. 258-263 (1998) 164.

[8] J.S. Hu, J.G. Li, X.M. Wang, J. Nucl. Mater. 363-365 (2007) 862-869;

J.S. Hu, J.G. Li, X.M. Wang, The HT-7 Team, Plasma Phys. 
Contr. Fusion 47 (8) (2005) 1271-1286.

[9] K.J. Gibson, G.F. Counsell, J. Curran, J. Nucl. Mater. 337-339 (4) (2005) 565.

[10] C.H. Skinner, N. Bekris, J.P. Coad, J. Nucl. Mater. 313-316 (5) (2003) 496

[11] F. Le Guern, F. Brygo, M. Tabarant, Proceedings of the 20th IEEE/NPSS Symposium on Fusion Engineering, 2003, pp. 9699.

[12] J.P. Coad, P. Andrew, D.E. Hole, J. Nucl. Mater. 313-316 (7) (2003) 419.

[13] J. Roth, V.Kh. Alimov, A.V. Golubeva, J. Nucl. Mater. 363-365 (2007) 822-826.

[14] M.J. Rubel, G. De Temmerman, G. Sergienko, J. Nucl. Mater. 363-365 (2007) 877-881.

[15] C. Hopf, V. Rohde, W. Jacob, J. Nucl. Mater. 363-365 (2007) 882-887.

[16] G. Vlad, in: M. Mutlu, G. Dinescu, R. Forch, J.M. Martin- Martinez, J. Vyskocil (Eds.), Plasma Polymers and Related Materials, Hacettepe University Press, 2005, ISBN 975-491- 194-0, pp. 84-90.

[17] K.J. Gibson, G.F. Counsell, C. Curran, J. Nucl. Mater. 337-339 (2005) 565-569.

[18] A. Widdowson, J.P. Coad, N. Bekris, J. Nucl. Mater. 363-365 (2007) 341-345.

[19] F. Brygo, A. Semerok, R. Oltra, Appl. Surf. Sci. 252 (23) (2006) 8314-8318.
[20] A. Semerok, S.V. Fomichev, J.M. Weulersse, J. Appl. Phys., submitted for publication.

[21] J.P. Coad, N. Bekris, J.D. Elder, J. Nucl. Mater. 290-293 (2001) 224.

[22] N. Bekris, C.H. Skinner, U. Berndt, J. Nucl. Mater. 313-316 (2003) 501.

[23] R.D. Penzhorn, N. Bekris, W. Hellriegel, J. Nucl. Mater. 279 (2000) 139.

[24] L. Gargiulo, J.J. Cordier, F. Samaille, Proceedings of the 24th SOFT Conference, Warsaw, Poland, 2006.

[25] J. Bucalossi, C. Brosset, A. Geraud, J. Nucl. Mater. 363-365 (2007) 759-763.

[26] F.L. Tabarés, D. Tafalla, V. Rohde, J. Nucl. Mater. 337-339 (1) (2005) 867-871.

[27] F.L. Tabarés, V. Rohde, Nucl. Fusion 45 (2005) L27.

[28] D.G. Whyte, J.W. Davis, J. Nucl. Mater. 337-339 (1) (2005) 560-564.

[29] O.I. Buzhinskij, V.G. Otroshchenko, D.G. Whyte, J. Nucl. Mater. 313-316 (2003) 214-218.

[30] J. Paméla, G.F. Matthews, V. Philipps, R. Kamendje, J. Nucl. Mater. 363-365 (2007) 1-11.

[31] R.A. Causey, W.R.Wampler, D.Walsh, J. Nucl. Mater. 176-177 (1990) 987;

R. Ochoukov, A.A. Haasz, J.W. Davis, Phys. Scripta T124 (2006) 27. 